\title{
Commentary: Location, location, location
}

\author{
Anthony L. Estrera, MD
}

From the Department of Cardiothoracic and Vascular Surgery, McGovern Medical School at UTHealth, Houston, Tex.

Disclosures: Dr. Anthony L. Estrera is a consultant for WL Gore.

Received for publication Oct 5, 2018; accepted for publication Oct 5, 2018; available ahead of print Nov 13, 2018. Address for reprints: Anthony L. Estrera, MD, Department of Cardiothoracic and Vascular Surgery, McGovern

Medical School at UTHealth, 6400 Fannin St, Ste 2850, Houston, TX 77030 (E-mail: Anthony.L.Estrera@ uth.tmc.edu).

J Thorac Cardiovasc Surg 2019;158:339-40

$0022-5223 / \$ 36.00$

Copyright (c) 2018 by The American Association for Thoracic Surgery

https://doi.org/10.1016/j.jtcvs.2018.10.019

Two decades ago, the primary approach to acute aortic dissection was simple: open ascending aortic replacement for type A; and optimal medical management for type B. We accepted this conservative stance, because the main goal was early survival. ${ }^{1}$

Continuing advances in cardiovascular surgery, however, have led to significant improvements in the early outcomes of acute repair-both in total arch replacement (TAR) for type A and thoracic endovascular aortic repair for type B. In addition, growing emphasis has been given to reducing late complications after dissection. ${ }^{2}$ Much focus has also been placed on identifying risk factors for late complications, such as larger total diameter, larger false-lumen diameter, tear location in the lesser curve of the arch, size of the tear, and number of tears. ${ }^{3-5}$

In their report in this issue of the Journal, Heo and colleagues ${ }^{6}$ have added to our understanding about the risk factors for late aneurysmal degeneration after aortic dissection. In their study, Heo and colleagues ${ }^{6}$ included only patients who underwent transverse TAR after acute type A aortic dissection, survived for follow-up, and had sufficient imaging for analysis. A thorough radiographic analysis was performed with parameters that were reasonable. Specifically, 40 patients met the criteria for evaluation, and the aorta was divided into 3 levels (upper descending, lower descending, and abdominal) in which tear locations and sizes were recorded. Interestingly, only intimal tears larger than $3 \mathrm{~mm}$ located in the upper descending thoracic aorta (zone 1) and number of visceral vessels arising from the false lumen were significant risk factors associated with late aortic dilatation.

As acknowledged by Heo and colleagues, ${ }^{6}$ the main limitation was the small cohort size. Despite this, some observations warrant mention:

1. Repaired type A dissection exhibits similar behavior to type B dissection with regard to natural history. Many previous reports on the late complications of repaired type A dissection included all repair types, ascending and hemiarch repair as well as TAR, and it is well recog-

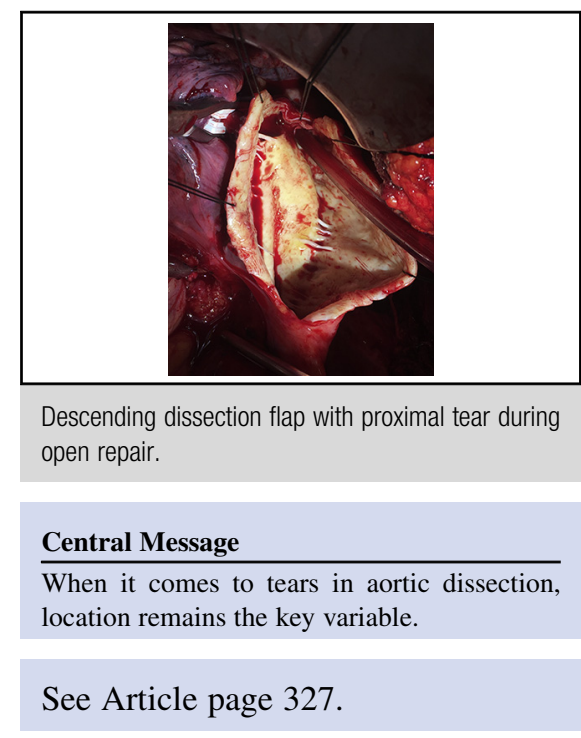

nized that a significant risk for distal transverse arch and proximal descending thoracic aneurysm formation is increased when less extensive repairs are performed. Heo and colleagues ${ }^{6}$ included only TAR procedures, eliminating the unrepaired arch as an issue. When repaired type A dissection included the transverse arch, the natural history appeared to be similar to that of acute type B aortic dissection.

2. When performing TAR for acute type A aortic dissection, frozen elephant trunk (FET) should be considered. Heo and colleagues ${ }^{6}$ reported no difference between TAR and TAR with FET in terms of late reintervention-and no difference in complete thrombosis of the false lumen at any level. They did, however, report $27 \%$ (7/26) distal endoleaks when TAR was performed without FET, which resulted in tears in zone 1 (the proximal descending thoracic aorta.) As would be expected, these were likely suture holes that occurred in the distal arch anastomosis. Despite this, Heo and colleagues ${ }^{6}$ recommended TAR with FET only when tears were identified in the proximal descending thoracic aorta at initial type A repair. Taking this one step further, performing the TAR with FET does not require more technical expertise than TAR alone, because the anastomoses are the same, but does provide a platform, the stent graft, to facilitate future endovascular interventions, if required. For those concerned with the increased risk of paraplegia with TAR and FET, the staged zone 2 repair may be considered. 
3. Tear location is important. Heo and colleagues ${ }^{6}$ corroborate others' work analyzing tear size and location and their relationships to late complications. It can be speculated that the larger tears located in the proximal descending thoracic aorta lead to increased pressures in the false channel-especially when there are no outflow fenestrations. ${ }^{8}$ It remains unknown how the increased pressures affect the integrity of the dissected aortic wall, leading to aneurysmal degeneration.

Accepting that this report is limited by its small cohort size, it still corroborates others' work analyzing risk factors for late complications after acute aortic dissection. In summary, when talking about tears in aortic dissection, it is all about location, location, location.

\section{References}

1. Elefteriades JA. What operation for acute type A dissection? J Thorac Cardiovasc Surg. 2002;123:201-3.
2. Pape LA, Awais M, Woznicki EM, Suzuki T, Trimarchi S, Evangelista A, et al. Presentation, diagnosis, and outcomes of acute aortic dissection: 17-year trends from the international registry of acute aortic dissection. J Am Coll Cardiol. 2015;66:350-8.

3. Evangelista A, Salas A, Ribera A, Ferreira-González I, Cuellar H, Pineda V, et al. Long-term outcome of aortic dissection with patent false lumen: predictive role of entry tear size and location. Circulation. 2012;125:3133-41.

4. Tolenaar JL, van Keulen JW, Trimarchi S, Jonker FH, van Herwaarden JA, Verhagen HJ, et al. Number of entry tears is associated with aortic growth in type B dissections. Ann Thorac Surg. 2013;96:39-42.

5. Ray HM, Durham CA, Ocazionez D, Charlton-Ouw KM, Estrera AL, Miller CC III, et al. Predictors of intervention and mortality in patients with uncomplicated acute type B aortic dissection. J Vasc Surg. 2016;64:1560-8.

6. Heo W, Song SW, Kim TH, Lee JS, Yoo KJ, Cho BK, et al. Differential impact of intimal tear location on aortic dilation and reintervention in acute type I aortic dissection after total arch replacement. J Thorac Cardiovasc Surg. 2019;158: 327-38.e2.

7. Desai ND, Hoedt A, Wang G, Szeto WY, Vallabhajosyula P, Reinke M, et al. Simplifying aortic arch surgery: open zone 2 arch with single branched thoracic endovascular aortic repair completion. Ann Cardiothorac Surg. 2018;7:351-6.

8. Girish A, Padala M, Kalra K, McIver BV, Veeraswamy RK, Chen EP, et al. The impact of intimal tear location and partial false lumen thrombosis in acute type B aortic dissection. Ann Thorac Surg. 2016;102:1925-32. 